\title{
Insights into Men's Sexual Aggression Toward Women: Dehumanization and Objectification
}

\author{
Casey L. Bevens ${ }^{1}$ (D) Steve Loughnan ${ }^{1}$
}

Published online: 26 February 2019

(C) The Author(s) 2019

\begin{abstract}
Sexual aggression is a global, ongoing problem, and it is most often perpetrated by men against women. In a set of studies, we investigated the role of dehumanization and objectification in men's sexual aggression-related attitudes and interests toward women in general, as well as toward a specific female target. The first of our studies, with 190 heterosexual British men recruited online, established a correlational link between dehumanization and rape proclivity. Dehumanization was also related to unfavorable attitudes toward rape victims. Critically, our results largely held when controlling for several variables with previously established relationships to sexual aggression. Results for objectification were less consistent. Our second study sought to experimentally manipulate the dehumanization of a woman and measures its effect on sexual aggression attitudes and interests. Results from 106 heterosexual British men seemed to be particularly driven by one aspect of dehumanization - the denial of human uniqueness - showing differences in correlations between experimental groups on measures of sexual aggression including rape proclivity, unfavorable attitudes toward a rape victim, and a behavioral rape analogue task. Avenues for future research are discussed, and implications of the work include the potential for emphasizing women as people, especially through highlighting their human uniqueness, in designing effective prevention and interventions (e.g., bystander) efforts.
\end{abstract}

Keywords Dehumanization $\cdot$ Sexual objectification $\cdot$ Sexual assault perpetration $\cdot$ Violence $\cdot$ Aggression toward women $\cdot$ Rape

Beauty provokes harassment, the law says, but it looks through men's eyes when deciding what provokes it. The Beauty Myth, Naomi Wolf (1990).

In the era of \#MeToo (https://metoomvmt.org/), with ever increasing prevalence of sexual aggression in the popular press and international consciousness, identifying men who may be more likely to perpetrate sexual aggression is an essential task that requires a strong base in empirical evidence. Recently (Reston 2018), compelling and emotionally provocative testimony of the experience of a sexual assault from Dr. Christine Blasey Ford was delivered to the United States senate judiciary committee in relation to the (ultimately successful) confirmation of Brett Kavanaugh to the Supreme Court. The widely viewed broadcast of her

Casey L. Bevens

caseylynnbevens@gmail.com

1 Department of Psychology, University of Edinburgh, 7 George Square, Edinburgh EH8 9JZ, UK words drove home for many how common these types of experiences continue to be in the lives of women, echoing similar testimony from Anita Hill concerning her experiences of sexual harassment, given against Justice Clarence Thomas a full 17 years earlier in 1991 (Jacobs 2018). Although we now seem to be well aware of the problem of sexual aggression perpetration, changing it is another issue entirely that should be treated with urgency as well as scientific rigor because of its complexity and its impact on the lives of so many.

Indeed, sexual aggression continues to be a major problem across the world that disproportionately effects women and girls (Garcia-Moreno et al. 2006; Smith et al. 2017). For the purposes of our paper, the term sexual aggression is used inclusively to indicate a continuum of manifestations of unwanted sexual behaviors that cover all acts of unwanted sexual contact from sexual harassment up to and including rape. Although men can be the victims of sexual aggression, the large and clear majority of these assaults are committed by men against women (see Basile et al. 2007; Breiding et al. 2014; Fisher et al. 2010; Muñoz-Rivas et al. 2009; Stoltenborgh et al. 2011; Tjaden and Thoennes 1998; Walby and Allen 2004), and thus men's sexual aggression is the focus 
of the present work. Specifically, we sought to examine socialand individual-level factors that relate to male endorsement of sexually aggressive attitudes and interests, which have in turn been shown to relate to behavioral self-reports of perpetration of sexual aggression (Abbey et al. 1998, 2001; Johnson et al. 2017; Malamuth 1989; Pryor 1987). The clarification of both social and individual factors that contribute to men's attitudes and interests regarding sexual aggression is an important and necessary task in helping better the lives of women and ultimately preventing the regular perpetuation of this type of violence against them.

Although we have long sought the answer to the seemingly straightforward question of why some men commit these assaults, the answer itself is not so straightforward, and no single unifying explanatory theory of the causes of sexual aggression dominates the existing literature. However, many attempts at such a theory have been put forward (Anderson et al. 1997; Gannon et al. 2008), reflecting at the meta-level the complexity of this phenomenon. These attempts can be broken down into some general categories (see Gannon et al. 2008, for a very useful in-depth discussion of the following works) including taxonomies (e.g., the Massachussets Treatment Center Rapist Typology: Version 3, Knight and Prentky 1990), micro and rehabilitation theories (e.g., the Relapse Prevention Model, Pithers 1990; the Self-regulation Model, Ward and Hudson 1998), single factor theories (e.g., psychodynamic theory, feminist theories, evolutionary theories, and social-cognitive theories), and multi-factor theories (e.g., the Confluence Model, Malamuth 1996; Integrated Theory, Marshall and Barbaree 1990; the Quadripartite Model, Hall and Hirschman 1991; and the Integrated Theory of Sexual Offending, Ward and Beech 2005). Even the briefest examination of the range of existing ideas and data in this well debated area contextualizes the present research's necessary decision to seek the broadest possible test of our own contributions to the literature.

For example, even in relation to a single commonly cited model - the Confluence Model (Malamuth 2003; Malamuth et al. 1991, 1995, 1996) — debate about the ongoing need for refinement persists because it by no means accounts for all variables that have been identified as associated with sexual aggression. The benefits of an updated model have been argued in multiple ways, from the simple incorporation of additional personality factors (e.g., sub-clinical psychopathy; Abbey et al. 2011) to an overall expansion and integration of the original model in the form of an interaction model (Malamuth et al. 2013). In light of this ongoing theoretical debate in the literature on sexual aggression, which continues to consider a wide range of known associated factors and to conduct tests that control for these, it is necessary to better understand the bigger picture of this important and contested phenomenon. This holistic view is especially important when looking at factors that are novel within the literature, as done in the present work, because robust tests will ensure that new studies add constructively to the literature rather than further muddy the waters. Specifically, we examine whether dehumanization and objectification may be useful additions.

\section{Dehumanization and Objectification}

The tendency to engage in dehumanization and objectification represent two potentially important influences on sexual aggression that have thus far been relatively unexplored within this broad literature. Dehumanization is the process of perceiving and/or treating people as less than human, which can manifest in several ways (for a review see Haslam and Loughnan 2014). Dehumanization is conceptually related to objectification, which itself can be viewed as a particular manifestation of the overarching concept, and objectification is treated thus for the purposes of this paper. Some ways in which dehumanization can be accomplished are though treating a person as an object (as in objectification) or as an animal. More subtly, it can be achieved by denying a given person certain human attributes (e.g., Haslam et al. 2005; Leyens et al. 2001), such as traits associated with human uniqueness or human nature. Human nature traits include those traits that can be considered core human attributes, such as emotionality and curiosity, whereas human uniqueness traits are qualities that distinguish people from animals, such as rationality and logic. The respective denial of these two groupings of traits results in two forms of dehumanization: mechanistic and animalistic (Haslam 2006). The consequences of dehumanization are not negligible and have been shown to extend to aggression at both the group (Leidner et al. 2013) and individual (Bastian et al. 2012; Greitmeyer and McLatchie 2011) levels.

Objectification, on the other hand and in the broadest sense, involves equating a person with a thing (Fredrickson and Roberts 1997), although other more nuanced theoretical conceptualizations exist (Nussbaum 1999). Objectification is an antecedent to a wide range of negative outcomes, particularly for women (Calogero 2004; Calogero et al. 2005; Fredrickson et al. 1998; Guizzo and Cadinu 2017; Moradi et al. 2005; Noll and Fredrickson 1998; Sanchez and Kiefer 2007; Steer and Tiggemann 2008; Szymanski and Henning 2007; Tiggeman and Kuring 2004; Tylka and Hill 2004). Combined, the evidence from this now long-standing field of research strongly supports the conclusion that objectification is both directly and indirectly related to a multitude of negative outcomes for women (for a review, see Moradi and Huang 2008). 
Highlighting the interrelated nature of the constructs of dehumanization and objectification, objectified targets have been shown to be denied the mental states associated with being human (Heflick and Goldenberg 2009; Loughnan et al. 2010), and dehumanization can occur when evaluating women who are sexually objectified (Vaes et al. 2011). When breaking down dehumanization based on denial of human nature or human uniqueness, it has also been found that specific forms of objectification uniquely map onto these. Objectification based on sexualization of a given woman is more likely to relate to animalistic dehumanization, whereas objectification based on valuing appearance more readily relates to mechanistic dehumanization (Morris et al. 2018). Furthermore, like classic self-objectification, internalization of dehumanizing traits occurs for people who are objectified, resulting in them seeing themselves as lacking in humanity (Loughnan et al. 2017). Thus, we examine both constructs as predictors in the present study in order to parse out their relative contributions to sexual aggression-related attitudes and interests in men.

\section{Dehumanization, Objectification, and Sexual Aggression}

It is possible that sexual aggression is a relatively unexplored consequence of engaging in dehumanization in general and/or objectification in particular. As we noted, the dehumanization of others has been empirically linked to heightened aggression in general (Bastian et al. 2012; Greitmeyer and McLatchie 2011; Leidner et al. 2013). Recent work has shown that there also exists a link between objectification and increased general physical aggression against women (Vasquez et al. 2017), mirroring the link between dehumanization and aggression. People are also less likely to help an objectified woman who is the victim of intimate partner violence (Pacilli et al. 2017), which although not sexual in nature, is similarly often committed by men against women (Tjaden and Thoennes 2000). Furthermore, objectification has been theoretically linked to the perpetration of sexual aggression in particular (Dworkin and MacKinnon 1985, 1988; Kelland 2011), and indeed, there is some empirical research into the potential relationship between objectification and sexual aggression. In one study where a fictitious woman reported being the victim of rape, higher levels of victim dehumanization and objectification (in the form of sexualization) increased victim-blame and reduced some elements of perceived suffering (Loughnan et al. 2013). In sum, both dehumanization and objectification have been linked to physical violence against women, and objectification is further linked to blaming the victims of sexual aggression.
The impact of objectification on rape victimization extends beyond negative perceptions of victims. Men who dehumanize women in an implicit associations test (IAT) to a greater degree (i.e., by associating them to either animals or objects) not only report more negative attitudes toward women who have been raped but also express greater willingness to rape and sexually harass (Rudman and Mescher 2012). The same authors found that men who implicitly related women to either objects or animals scored higher on rape proclivity; furthermore, those men who implicitly linked women with animals were more likely to aggress against women in the laboratory using a rape behavior analogue. In short, sexual objectification is linked to negative and harmful implicit attitudes about victims of sexual aggression, as well as increased interest in and endorsement of analogous behaviors.

\section{The Present Studies}

The body of work discussed thus far presents initial evidence that there is some relationship among dehumanization, objectification, and sexual aggression. However, these studies stop short of examining the predictive roles of dehumanization and objectification on men's explicit self-report measures of sexual aggression attitudes and interests as the primary outcomes. Likewise, they fail to control for individual differences in known correlates of sexual aggression. Thus, it is not clear whether the roles of dehumanization and objectification as currently established in the literature are actually enhancing our understanding of sexual aggression against women or whether the constructs are simply acting as proxies for established third-factor effects. In other words, we have not ruled out the possibility that the previously studied effects of dehumanization and objectification on sexual aggression can be otherwise accounted for by variability from other known related constructs. The present work seeks to fill this gap. Knowing that objectification has been linked to general physical aggression (Vasquez et al. 2017) and attitudes about women who are victims of intimate partner violence (Pacilli et al. 2017), it follows that such a robust investigation of its role in sexual aggression is appropriate and timely.

Although some studies to date have looked at dehumanization and/or objectification within the context of sexual aggression, their approaches have been somewhat periphery. Those previous studies which have used sexual objectification as a predictor only looked at outcomes concerning specific attitudes about specific victims (e.g., blame; Loughnan et al. 2013) or attitudes about specific perpetrators (e.g., blame; Bernard et al. 2015). Those studies which examined men's sexual aggression interests and behavior as an outcome either treated dehumanization as an implicit measure (Rudman and 
Mescher 2012) or objectification as a mediator in the specific and limited context of alcohol use (Gervais et al. 2014; Haikalis et al. 2015). The present set of studies aims to partially replicate and extend this line of recent research, filling the gap by directly and explicitly examining the roles of dehumanization and objectification in men's sexual aggressionrelated attitudes and interests. We seek to accomplish this goal in a pair of studies which first establish correlational evidence of this role, while controlling for other known correlates, and then experimentally test a causal relationship.

We conceptualize sexually aggressive attitudes and interests in the present work as rape proclivity, acceptance of unfavorable attitudes about rape victims, interest in sexual harassment, and additionally (in Study 2) a behavioral analogue of sexual aggression. No self-report measures of actual perpetration behaviors are used in accordance with the British Psychological Association's Code of Human Research Ethics (because asking about illegal behaviors constitutes more than minimal risk to participants). The control factors tested in Study 1 all have theoretical and/or correlational links to sexual aggression based on prior literature, including hostile and benevolent sexism (Abrams et al. 2003; Masser et al. 2006), narcissism (Bushman et al. 2003), psychopathy (Hersh and Gray-Little 1998; Kosson et al. 1997), physical aggression (Lackie and de Man 1997), sexual sadism (Heilbrun and Loftus 1986), and general sexual promiscuity (Yost and Zurbriggen 2006). Additionally, we included several aspects of masculinity which have been associated with objectification and sexual aggression (Mikorski and Szymanski 2016; Seabrook et al. 2016): the role of contingency of self-worth on masculinity and conformity to certain masculine norms (i.e., risk-taking, violence, power over women, and being a "playboy").

\section{Study 1}

In our first study we sought to examine whether men's dehumanization and objectification of women relates to their sexual aggression attitudes and interests above and beyond a range of previously established related factors. Specifically, we sought to assess (a) whether dehumanization and objectification of women in general correlate with men's sexually aggressive attitudes and interests and (b) whether this relationship is maintained when controlling for specific individual differences.

Although our first study was largely exploratory, with no a priori predictions being made about the impact of specific control variables or differences in manifestations of dehumanization (e.g., human nature vs. human uniqueness), we sought to establish initial strong evidence for a direct link between dehumanization and objectification with sexually aggressive attitudes and interests in men. We did expect that there would be relationships between both dehumanization and objectification with all sexual aggression factors that would act as a foundation to experimental tests of causation.

\section{Method}

\section{Participants}

Our study was reviewed and approved by the institutional ethics board of a large United Kingdom university for compliance with standards for the ethical treatment of human participants prior to study recruitment. A total of 225 men were recruited through an online site, Prolific Academic, and were paid $£ 1.50$ (approx. \$2). Thirteen failed to complete three or more scales, and 22 people began the study and failed to complete it, leaving a final sample of 190 men. All participants were British male adults who identified as heterosexual. Due to the sensitive nature of the topic, and in hopes of encouraging truthful responding by emphasizing anonymity, no further demographic data were gathered. Prior to full data collection, ten initial participants were run, and we noticed that due to a survey software issue, they were skipping or responding invalidly to a crucial measures, the Other Objectification Questionnaire (OOQ). Their data were not examined in relation to study hypotheses at this time, and the problem was corrected within the Qualtrics survey mechanics platform prior to continuing data collection. Thus, these ten participants' data were excluded on the OOQ only; they were retained on all other measures.

\section{Procedure and Measures}

Participants completed the study online. Following informed consent, all participants completed the Other Objectification Questionnaire (Noll and Fredrickson 1998) and the Human Nature and Human Uniqueness scales (Bastian et al. 2012). They all also completed three dependent variable measures relevant to sexual aggression: the Likelihood to Sexually Harass Scale (LSH; Pryor 1987), the Attraction to Sexual Aggression Scale's rape proclivity items (ASAI; Malamuth 1989), and the Attitudes toward Rape Victims Scale (ARVS; Ward 1988). To reduce fatigue, the control measures were split such that they were each completed by half the sample based on random assignment. The specific scales included for the two subsamples were chosen such that an equal number of items would be completed by each group. One half (102 men; reduced to 96) completed the Ambivalent Sexism Inventory (ASI; Glick and Fiske 1996), the Masculinity Contingency Scale's (MCS) threat scale (Burkley et al. 
2016), and four Conformity to Masculine Norms Inventory subscales (i.e., risk taking, violence, power over women, and playboy; Parent and Moradi 2011). The other half (101 men; reduced to 94) completed the Short Dark Triad (SD3) scales for narcissism and psychopathy (Jones and Paulhus 2014); the Multidimensional Inventory of Development, Sex, and Aggression's (MIDSA) sexual sadism subscales (Knight and Cerce 1999); and the physical aggression scale (Wrench 2002). The scale descriptions that follow conform to the order of presentation: dehumanization and objectification measures, then sexual aggression attitudes and beliefs measures, and lastly control measures.

Objectification The Self-Objectification Questionnaire (SOQ; Noll and Fredrickson 1998) is commonly used in objectification research. Strelan and Hargreaves (2005) modified the SOQ to measure the objectification of others, referring to this as the Other Objectification Questionnaire (OOQ). Employing the latter approach, we asked participants to rank the relative importance of appearance and competence attributes on their evaluation of the bodies of women. This scale has been used similarly with success in past research (Kozak et al. 2009; Loughnan et al. 2015). The scale consists of a total of ten items: five appearance-based (i.e., sex appeal, physical attractiveness, weight, measurements, and toned muscles) and five competence-based (i.e., health, physical fitness level, strength, coordination, and stamina). Participants' scores were calculated by separately summing the appearance and competence ranks, and then subtracting the sum of the competence ranks from the sum of the appearance ranks. This produced a score ranging from -25 to 25 , with higher scores reflecting greater objectification. For ease of interpretation, 25 was then added to all scores to create positive numbers.

Dehumanization To assess the tendency to deny human nature and human uniqueness, we asked participants to rate a specific woman, as is typical in the literature that has employed these scales. There were four human nature items (e.g., "[this woman] Is emotional, responsive, and warm"; Bastian et al. 2012), measured from 1 (Not at all) to 7 (Very much so) $(\alpha=.76)$. Similarly, there were four human uniqueness items (e.g., "[this woman] Is rational, logical, and intelligent"; Bastian et al. 2012), measured from 1 (Not at all) to 7 (Very much so) $(\alpha=.70)$.

Sexual Harassment Interest The Likelihood to Sexually Harass Scale (LSH; Pryor 1987) consists of ten scenarios involving a man and a woman and in which male participants are asked to imagine themselves as the male character. To reduce participant fatigue, we modified this scale such that only the five shortest scenarios were used. In each scenario, the male character is in a position of power and three possible courses of action are listed. An example scenario is:

Imagine that you are a Hollywood film director. You are casting for a minor role in a film you are planning. The role calls for a particularly stunning actress, one with a lot of sex appeal. How likely are you to do the following things in this situation?

Participants are asked to assume there would be no consequences for their actions and then rate the likelihood of their engaging in three possible behaviors listed (e.g., as related to the example scenario: "Would you ask the actress to whom you were most personally attracted to talk with you about the role over dinner?") from 1 (Not at all likely) to 5 (Very likely). Only one of the three courses of action involves sexual harassment, and it is the five summed responses to these critical items across the five scenarios used that form participants' scale score. The critical response in relation to the example scenario is to the item asking: "Would [you] give the role to the actress who agreed to have sex with you?" Higher scores indicate higher likelihood to sexually harass $(\alpha=.90)$.

Rape Proclivity The Attraction to Sexual Aggression Inventory (ASAI; Malamuth 1989) measures attraction to various sexual behaviors, including those involved in conventional, unconventional, and deviant sex. For our study, only those 14 items assessing attitudes related specifically to rape and sexual assault were used because they were most relevant to our research question. An example item from this scale is: "How arousing would it be to force a female to do something sexual she did not want to do," rated from 1 (Not Very Arousing) to 5 (Very Arousing). Mean participant scores were calculated, with higher scores indicating greater rape proclivity $(\alpha=.91)$.

Unfavorable Attitudes Toward Rape Victims The Attitudes toward Rape Victims Scale (ARVS; Ward 1988) consists of 25 items assessing attitudes concerning victims of rape that correspond with common rape myth endorsement. For example, "the extent of the woman's resistance should be the major factor in determining if a rape has occurred," measured from 1 (Strongly Disagree) to 5 (Agree Strongly). Participants' scores were computed by summing the responses across items, with higher scores indicative of more unfavorable attitudes toward rape victims $(\alpha=.91)$.

Ambivalent Sexism The Ambivalent Sexism Inventory is a 22item scale (Glick and Fiske 1996) measuring two facets: benevolent sexism (BS; $\alpha=.84$ ) and hostile sexism (HS; 
$\alpha=.94$ ), scaled from 1 (Disagree Strongly) to 6 (Agree Strongly). An example item from the benevolent sexism subscale is: "No matter how accomplished he is, a man is not truly complete as a person unless he has the love of a woman," whereas an example of an item from the hostile sexism subscale is: "Women seek to gain power by getting control over men." These related, yet functionally distinct, aspects of sexism are reflected in the two subscales of the measure. Scores for each subscale were averaged, and higher scores indicate stronger levels of sexism.

Masculinity Factors The Masculinity Contingency Scale (MCS; Burkley et al. 2016) measures the extent that men's self-worth and identity depend on their personal masculinity, without relying on specific, often culturally dependent norms. We employed the five-item threat subscale, which assesses how much one's sense of self-worth is threatened by failure to live up to the demands of masculinity (e.g., "My self-worth suffers if I think my manhood is lacking"), rated from 1 (Strongly Disagree) to 5 (Strongly Agree). The threat subscale is more related to negative outcomes for men than the un-used subscale related to boosting self-worth through masculinity (Burkley et al. 2016). Scores were computed by averaging across items, with higher scores indicating greater contingency of self-worth based on masculinity, $\alpha=.88$.

The Conformity to Masculine Norms Inventory-46 (CMNI-46; Parent and Moradi 2009; Parent and Moradi 2011) measures conformity to specific masculinity norms. We employed four subscales, totaling 19 items, which were the most theoretically relevant to sexual aggression: risk taking (e.g., "I frequently put myself in risky situations," $\alpha=.87$ ), violence (e.g., "Sometime violent action is necessary," $\alpha=.82$ ), power over women (e.g., "In general, I control the women in my life," $\alpha=.79$ ), and playboy (e.g., "If I could, I would frequently change sexual partners," $\alpha=.80$ ). All items were rated from 1 (Strongly Disagree) to 4 (Strongly Agree), with higher mean scores indicating greater conformity to masculine norms.

Dark Triad/Tetrad Personality Factors The dark triad is a constellation of traits including narcissism, psychopathy, and Machiavellianism, which are associated with non-pathological, yet negative and "dark" personalities (Paulhus and Williams 2002). In addition, emerging literature has suggested a fourth dimension, sadism, forms a "dark tetrad" of personality traits with these others (Chabrol et al. 2009). We measured psychopathy, narcissism, and sadism. We did not measure Machiavellianism because we did not expect it to predict sexual aggression based on lack of theoretical relevance as well as lack of prior literature making such a link. We employed the Short Dark Triad (SD3; Jones and Paulhus 2014), which has nine items per scale, rated from 1 (Disagree Strongly) to 5 (Agree Strongly), to measure narcissism (e.g., "Many group activities tend to be dull without me," $\alpha=.69$ ) and psychopathy (e.g., "Payback needs to be quick and nasty," $\alpha=.70$ ). Participants' mean scores were computed for each scale, with higher scores indicative of stronger endorsement of each factor. We measured sexual sadism using the Multidimensional Inventory of Development, Sex, and Aggression (MIDSA; Knight and Cerce 1999; Knight et al. 1994; MIDSA 2011). The two subscales we used in our study were the seven-item sadistic fantasy subscale (e.g., "I have thought about embarrassing or humiliating a woman or girl during sex," $\alpha=.77$ ) and the eight-item sadistic behavior subscale (e.g., "I have purposely hurt a woman or girl physically during sex," $\alpha=.83$ ). Both range responses from 1 (Disagree Strongly) to 5 (Agree Strongly), with higher mean scores indicating greater endorsement of sexual sadism.

Physical Aggression The Physical Aggression Scale (Wrench 2002 ) is a 15 -item scale measuring general physical aggression across three factors: object violence, physical confrontation, and control. Responses are made on a scale ranging from 1 (Strongly disagree) to 5 (Strongly agree), scores were averaged across all items, and higher overall scores indicate greater aggression $(\alpha=.85)$. A sample item is: "When I get upset, I have a tendency to throw objects."

\section{Results}

\section{Analysis Plan and Supplements}

Initial $t$-tests confirmed that there were no significant differences between the two subsamples that were collected on measures of dehumanization, objectification, or sexual aggression ( $p \mathrm{~s}>.227$ ), and thus the groups were combined into a single sample for analysis. Pearson's correlations and descriptive statistics were then computed for all measures in relation to the primary variables of interest and these can be found in Table 1.

We next sought to test the relative contributions of objectification, human nature, and human uniqueness to each of the sexual aggression attitudes outcome measures (rape proclivity, unfavorable attitudes toward rape victims, and sexual harassment interest) by running three individual initial regression models (one for each outcome). We then tested the predictor variables retained in each of these initial models against control variables that were correlated with the given outcome to determine if their contribution would remain significant when taking each of these factors into account. To help control for overall error, only variables with correlations at or below the significance level of .001 were entered into these models.

Compiled materials and measures can be viewed at https:// osf.io/v3d8x/. Additional analyses for Study 1 were run, including using bootstrapping for all regression models. These produced a similar pattern of results to those reported 
Table 1 Study 1 descriptive statistics and correlations among study variables, study 1

\begin{tabular}{|c|c|c|c|c|c|c|c|c|}
\hline & \multirow[b]{2}{*}{$M(S D)$} & \multirow{2}{*}{$\begin{array}{l}n \text { (Possible } \\
\text { Scores) }\end{array}$} & \multicolumn{6}{|c|}{ Correlations } \\
\hline & & & 1 & 2 & 3 & 4 & 5 & 6 \\
\hline \multicolumn{9}{|l|}{ Main Variables } \\
\hline 1. Objectification & $20.49(11.13)$ & $182(0-50)$ & - & & & & & \\
\hline 2. Human Nature & $4.97(1.05)$ & $189(1-7)$ & .029 & - & & & & \\
\hline 3. Human Uniqueness & $5.00(.96)$ & $188(1-7)$ & -.014 & $.742 * * *$ & - & & & \\
\hline 4. LSH & $8.46(4.79)$ & $190(0-25)$ & $-.203 * * *$ & -.133 & -.070 & - & & \\
\hline 5. ASAI & $1.37(.53)$ & $190(1-5)$ & $-.167^{*}$ & $-.261 * * *$ & $-.165^{*}$ & $.513 * * *$ & - & \\
\hline 6. ARVS & $1.62(.58)$ & $190(1-5)$ & -.094 & $-.187 *$ & $-.234 * * *$ & $.460 * * *$ & $.429 * * *$ & - \\
\hline \multicolumn{9}{|l|}{ Control Variables } \\
\hline Narcissism & $2.47(.70)$ & $94(1-5)$ & -.007 & -.155 & -.183 & $.275^{* * *}$ & $.217^{*}$ & $.323 * * *$ \\
\hline Psychopathy & $2.09(.65)$ & $94(1-5)$ & $-.232 *$ & -.128 & -.060 & $.546^{* * *}$ & $.423 * * *$ & $.506 * * *$ \\
\hline Physical Aggression & $1.88(.63)$ & $94(1-5)$ & -.122 & -.103 & -.092 & $.464 * * *$ & $.446^{* * *}$ & $.447 * * *$ \\
\hline Sadistic Fantasy & $1.32(.43)$ & $93(1-5)$ & .004 & -.142 & -.048 & $.344 * * *$ & $.205^{*}$ & $.260^{*}$ \\
\hline Sadistic Behavior & $1.29(.43)$ & $94(1-5)$ & -.026 & -.117 & .007 & $.244 *$ & .072 & $.222 *$ \\
\hline Benevolent Sexism & $3.29(.94)$ & $95(1-6)$ & -.136 & -.016 & -.145 & $.222 *$ & .182 & $.266 * * *$ \\
\hline Hostile Sexism & $3.04(1.11)$ & $95(1-6)$ & -.160 & $-.397 * * *$ & $-.480 * * *$ & $.322 * * *$ & $.288 * * *$ & $.616^{* * *}$ \\
\hline Masculine Contingency & $2.20(1.02)$ & $93(1-5)$ & $-.257^{*}$ & -.169 & $-.296 * * *$ & $.336 * * *$ & .130 & $.433 * * *$ \\
\hline Masculine Norm: Risk & $2.15(.60)$ & $95(1-4)$ & -.077 & -.194 & $-.210^{*}$ & $.311 * * *$ & $.204 *$ & $.351 * * *$ \\
\hline Masculine Norm: Violence & $2.42(.54)$ & $95(1-4)$ & -.144 & -.183 & -.126 & $.310 * * *$ & .150 & $.349 * * *$ \\
\hline Masculine Norm: Power & $1.67(.62)$ & $95(1-4)$ & -.140 & $-.308 * * *$ & $-.379 * * *$ & $.443 * * *$ & $.477 * * *$ & $.619 * * *$ \\
\hline Masculine Norm: Playboy & $2.30(.71)$ & $95(1-4)$ & -.185 & -.027 & .048 & $.426 * * *$ & .243 & $.228 *$ \\
\hline
\end{tabular}

LSH Likelihood to Sexually Harass (measuring sexual harassment interest), ASAI Attraction to Sexual Aggression Inventory (measuring rape proclivity), ARVS Attitudes toward Rape Victims Scale (measuring unfavorable attitudes toward rape victims)

$* p<.05 . * * * p<.001$

here and can be found in the authors' online supplementary analyses (https://osf.io/r832j/ \& https://osf.io/s6p3k/). All data for this project are open access, and data for Study 1 can be accessed at https://osf.io/24zbw/ .

\section{Rape Proclivity (ASAI)}

The ASAI was positively correlated at $p \leq .001$ with both the other sexual aggression attitudes measures and four of the control variables (i.e., the masculine norm of power over women, physical aggression, psychopathy, and hostile sexism) (see Table 1). Of note, the correlation with objectification was in the opposite direction from predictions. We then ran a regression model to test the relative contributions of dehumanization and objectification measures to rape proclivity (Model 1 in Table 2). In this initial regression model, objectification, human nature, and human uniqueness were entered (Adj. $\left.R^{2}=.08\right)$. Both objectification $(b=-.01, S E=.00, \beta=-.15$, $p=.034)$ and human nature $(b=-.14, S E=.05, \beta=-.29$, $p=.007)$ were found to be significant predictors of rape proclivity.

Next, objectification and human nature were tested against the four control variables of interest (based on their correlations with rape proclivity) in a series of hierarchical regressions (Models 2-5 in Table 2). For each of these models, in Step 1 objectification and human nature were entered. In Step 2 of each model individual control variables were entered: the masculine norm of power over women (Model 2), physical aggression (Model 3), psychopathy (Model 4), and hostile sexism (Model 5). These results show that in Step 2, objectification was not retained in any models. Neither objectification nor human nature was retained when controlling for psychopathy or physical aggression. However, human nature was retained in Step 2 when tested against hostile sexism $(p=.014)$ and the masculine norm of power over women $(p=.029)$. Thus, human nature continued to significantly contribute to rape proclivity while controlling for two of four additional predictors.

\section{Unfavorable Attitudes Toward Rape Victims (ARVS)}

The ARVS was positively correlated at $p \leq .001$ with both the other sexual aggression attitude measures and nine control variables (the masculine norm of power over women, hostile sexism, psychopathy, physical aggression, masculine contingency, the masculine norm of risk taking, the masculine norm 
Table 2 Hierarchical linear regression models predicting rape proclivity, study 1

\begin{tabular}{|c|c|c|c|c|c|c|c|c|c|c|c|c|c|c|c|c|}
\hline \multirow[b]{2}{*}{ Variables } & \multirow[b]{2}{*}{ Step } & \multicolumn{3}{|c|}{ Model 1} & \multicolumn{3}{|c|}{ Model 2} & \multicolumn{3}{|c|}{ Model 3} & \multicolumn{3}{|c|}{ Model 4} & \multicolumn{3}{|c|}{ Model 5} \\
\hline & & $\beta$ & $\mathrm{b}$ & $t$ & $\beta$ & $\mathrm{b}$ & $t$ & $\beta$ & $\mathrm{b}$ & $t$ & $\beta$ & $\mathrm{b}$ & $t$ & $\beta$ & $\mathrm{b}$ & $t$ \\
\hline \multirow[t]{2}{*}{ Objectification } & 1 & -.15 & -.01 & $-2.17^{*}$ & -.14 & -.01 & -1.45 & -.17 & -.01 & -1.60 & -.17 & -.01 & -1.60 & -.15 & -.01 & -1.50 \\
\hline & 2 & & & & -.11 & -.01 & -1.19 & -.12 & -.01 & -1.21 & -.08 & -.00 & -.78 & -.13 & -.01 & -1.32 \\
\hline \multirow[t]{2}{*}{ Human Nature } & 1 & -.26 & -.13 & $-3.69 * *$ & -.34 & -.15 & $-3.41 * *$ & -.19 & -.11 & -1.85 & -.19 & -.11 & -1.85 & -.33 & -.15 & $-3.31 * *$ \\
\hline & 2 & & & & -.21 & -.10 & $-2.23 *$ & -.14 & -.10 & -1.45 & -.14 & -.07 & -1.38 & -.27 & -.13 & $-2.51^{*}$ \\
\hline Masculine Norm: Power & 2 & & & & .39 & .31 & $4.08 * * *$ & & & & & & & & & \\
\hline Physical Aggression & 2 & & & & & & & .40 & .37 & $4.12 * * *$ & & & & & & \\
\hline Psychopathy & 2 & & & & & & & & & & .38 & .33 & $3.74 * * *$ & & & \\
\hline Hostile Sexism & 2 & & & & & & & & & & & & & .16 & .07 & 1.43 \\
\hline \multirow[t]{2}{*}{$F$} & 1 & \multirow{2}{*}{\multicolumn{3}{|c|}{$9.37 * * *$}} & \multicolumn{3}{|c|}{$7.28 * *$} & \multicolumn{3}{|l|}{2.95} & \multicolumn{3}{|l|}{2.94} & \multicolumn{3}{|c|}{$7.02 * *$} \\
\hline & 2 & & & & \multicolumn{3}{|c|}{$11.24 * * *$} & \multicolumn{3}{|c|}{$8.00 * * *$} & \multicolumn{3}{|c|}{$6.93 * * *$} & \multicolumn{3}{|c|}{$5.42 * *$} \\
\hline \multirow[t]{2}{*}{$\left(d f, d f_{\text {error }}\right)$} & 1 & \multirow{2}{*}{\multicolumn{3}{|c|}{$(2,179)$}} & \multicolumn{3}{|c|}{$(2,89)$} & \multicolumn{3}{|c|}{$(2,86)$} & \multicolumn{3}{|c|}{$(2,86)$} & \multicolumn{3}{|c|}{$(2,88)$} \\
\hline & 2 & & & & \multicolumn{3}{|c|}{$(3,88)$} & \multicolumn{3}{|c|}{$(3,85)$} & \multicolumn{3}{|c|}{$(3,85)$} & \multicolumn{3}{|c|}{$(3,87)$} \\
\hline \multirow[t]{2}{*}{ Adj. $R^{2}$} & 1 & \multirow{2}{*}{\multicolumn{3}{|c|}{.09}} & \multicolumn{3}{|l|}{.12} & .04 & & & .04 & & & .12 & & \\
\hline & 2 & & & & .25 & & & .19 & & & .17 & & & .13 & & \\
\hline$\Delta R^{2}$ & & & & & $.14 * *$ & & & $.16^{* *}$ & & & $.13 * *$ & & & .02 & & \\
\hline
\end{tabular}

$* p<.05 . * * p<.01 . * * * p<.001$

of violence, narcissism, and benevolent sexism) (see Table 1). In the initial regression model to test the relative contributions of dehumanization and objectification measures to unfavorable attitudes toward rape victims, objectification, human nature, and human uniqueness were entered (Adj. $R^{2}=.05$ ). Human uniqueness was the only significant predictor retained ( $b=-.14, S E=.07, \beta=-.23, p=.038)$. Thus, human uniqueness was then tested against the nine correlated control variables in a series of hierarchical regressions (Models 1-9 in Table 3). For each of these models, in Step 1 human uniqueness was entered, and in Step 2 individual control variables were entered. These models show that human uniqueness was retained in Step 2 when controlling for psychopathy ( $p=.038)$, benevolent sexism $(p=.025)$, and the masculine norm of violence $(p=.025)$. However, human uniqueness was not retained in Step 2 of the models testing against narcissism, physical aggression, hostile sexism, the masculinity contingency scale, or the masculine norms of risk taking and power over women. In sum, human uniqueness continued to contribute to negative attitudes toward rape victims in one-third of the models.

\section{Sexual Harassment Interest (LSH)}

The LSH scale was positively correlated with both the other sexual aggression attitudes measures and the majority of control measures (see Table 1). Of note, the correlation with objectification was in the opposite direction from our predictions. In the initial regression wherein objectification, human nature, and human uniqueness were entered (Adj. $R^{2}=.04$ ), only objectification significantly predicted sexual harassment interest $(b=-.09, S E=.03, \beta=-.20, p=.007)$ and was retained for testing against control variables. However, objectification did not remain significant in any of these additional models, except for when it was tested while controlling for the masculine norm of risk taking $(b=-.08, S E=.04, \beta=-.20$, $p=.048)$. In sum, objectification did not generally significantly contribute to men's likelihood to sexually harass when controlling for additional variables and was acting in opposition to our predictions.

\section{Discussion}

Results of Study 1 provide initial support for a correlational relationship between dehumanization and men's explicit endorsement of sexual aggression interest and beliefs. In multiple cases, this relationship emerged above and beyond the variance accounted for by relevant control variables. In the case of rape proclivity, human nature was retained in two of four models when tested against controls. The correlations between the controls that also correlated with rape proclivity (i.e., the masculine norm of power over women, psychopathy, physical aggression, and hostile sexism) may hint at an underlying personality construct. Endorsement of unfavorable 
Table 3 Hierarchical linear regression models predicting unfavorable attitudes toward rape victims, study 1

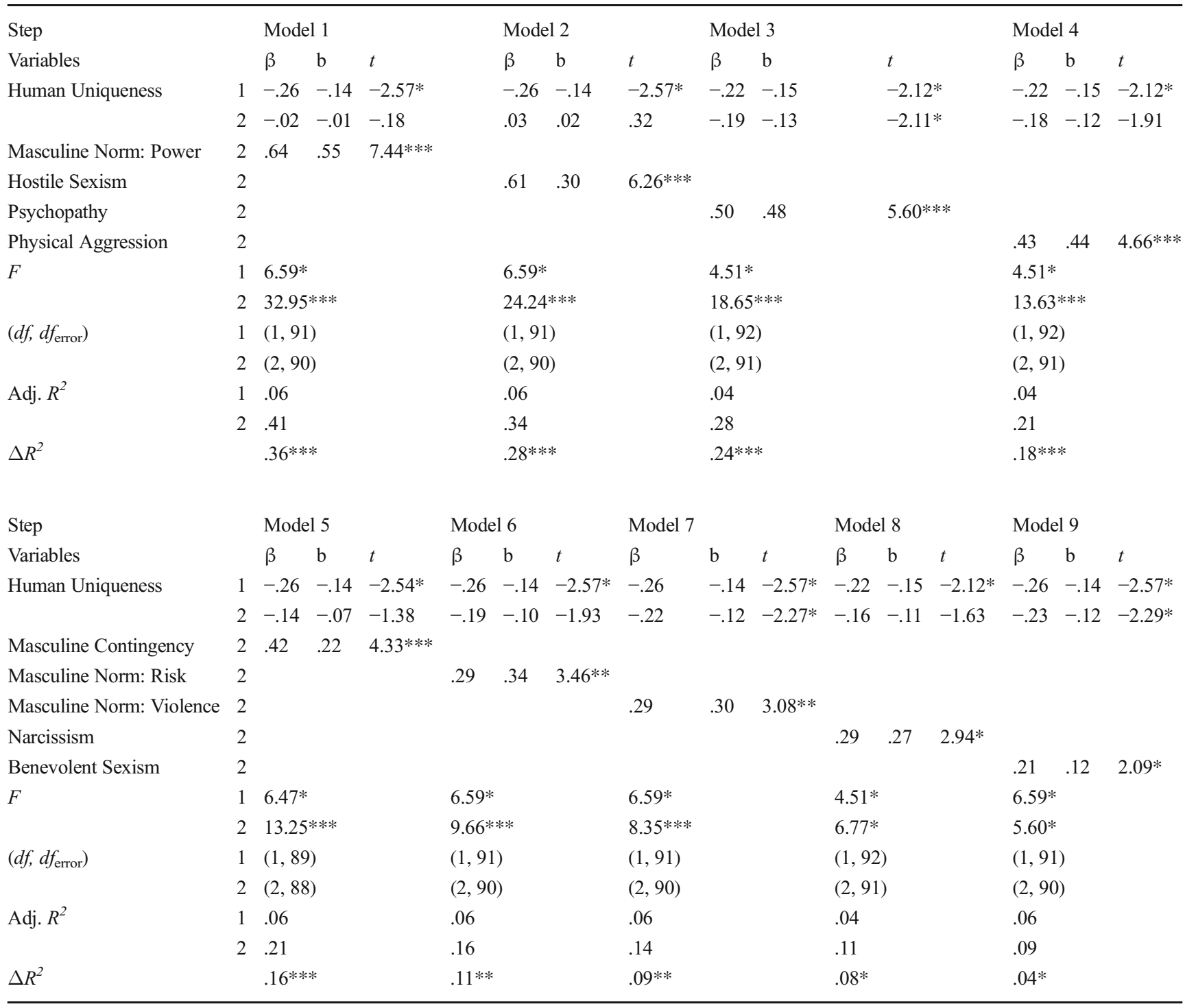

$* p<.05 . * * p<.01 . * * * p<.001$

attitudes toward rape victims retained human uniqueness in three of nine models tested. The involvement of different types of human qualities as relevant to rape proclivity versus unfavorable attitudes toward rape victims may indicate that there are differences between the role of dehumanization in attitudes about victims versus attitudes toward the act of sexual aggression itself.

Objectification yielded much less consistent results, indeed showing unexpected negative correlations with rape proclivity and likelihood to sexually harass, as well as generally failing to be maintained when controlling for other variables. On the less extreme end of our conceptualization of sexual aggression, interest in sexual harassment was in fact only correlated (negatively) with objectification, and not with measures of dehumanization. These odd results concerning objectification may be an artifact of the scale used, and results should therefore be interpreted with caution.

Despite some null and mixed findings for likelihood to sexually harass and objectification, the results for dehumanization remain strong across multiple outcomes, and they point to a robust relationship due to the amount of control exerted by including potential confounds. Dehumanization may come into play later in the progression of events leading up to violence. If sexual aggression is conceptualized as a continuum of severity ranging from sexual harassment to rape, as we did here, based on the results of Study 1, dehumanization is most 
relevant in contexts of extreme aggression and more severe forms of mistreatment. It is possible that dehumanization emerges as a form of self-justification as thoughts and attitudes escalate toward actual violence, and it is employed less consistently when assessing victims post-hoc. This possibility points to a potential avenue for further research on why and when some men sexually aggress.

\section{Study 2}

Our first study gave us the confidence to say that there is indeed some relationship between dehumanization and sexual aggression which cannot be accounted for entirely by previously established effects. However, our work leaves open the question of the nature of that relationship. Building on the correlational foundation laid in Study 1, we next sought in Study 2 to test the possibility of a causal influence of dehumanization on sexual aggression attitudes and interests. Thus, we experimentally manipulated the sexualization of a woman and measured the influence of this manipulation on men's sexually aggressive attitudes and behaviors toward that particular woman. We again conceptualized sexually aggressive attitudes as acceptance of unfavorable attitudes toward rape victims and interests as rape proclivity. Based on the results of Study 1, we did not measure interest in sexual harassment. Additionally, we examined a behavioral analogue for sexual aggression.

Study 2 was based in a larger body of work in which we ran a pair of very similar preliminary studies also seeking to experimentally manipulate the sexualization of a woman. The preliminary studies informed the methodology for the study reported here. Specifically, these differed methodologically from the present study only in the stimuli images used and the use of wording within measures to relate to women in general (vs. the particular woman, as done in the study reported). Of note, both preliminary studies $(n s=343$ and 106) largely replicated the correlations of interest from Study 1, and the results taken collectively across all studies represent robust evidence of these correlational relationships. Additionally, the images used in the present study (a control woman in everyday clothing vs. the same woman in sexualized attire) were pre-tested with an online sample to verify that they differed in how the woman depicted was perceived along the dimensions of dehumanization and objectification. They did differ, such that the image of the sexualized woman was attributed lower levels of human nature and human uniqueness, as well as higher levels of objectification, in comparison to the control woman. (An interested reader can view the details of the broader work that was conducted in relation to Study 2 online (https://osf.io/r832j/). Compiled materials and measures for Study 2 can be found at https://osf.io/mxq78/. All data for this study are open access (https://osf.io/xuhr6/).
In the present study, condition (control vs. sexualized) was treated as the primary predictor, with human nature and human uniqueness serving as manipulation checks, because sexualization has been shown to increased dehumanizing and objectifying perceptions of women (Heflick and Goldenberg 2009; Loughnan et al. 2010, 2013). Study 2's outcome variables included a Rape Behavior Analogue (Rudman and Mescher 2012) in addition to modified versions (re-worded slightly to relate to the specific woman) of the ASAI (measuring rape proclivity) and ARVS (measuring unfavorable attitudes toward a rape victim). We expected that group differences would emerge based on condition, showing greater endorsement of sexual aggression attitudes and interests, as well as a higher number of behaviors in the behavioral analogue, when the woman was sexualized. Because the methodology of Study 2 relates to the woman in our manipulation (participants were asked how they would treat her), our second study also improved on Study 1 by better aligning with real-world violence, where the process and costs of dehumanization and objectification are directed toward a given women, not women in general.

\section{Method}

\section{Participants}

The present study was reviewed and approved by the institutional ethics board of a large United Kingdom-based university for compliance with standards for the ethical treatment of human participants prior to recruitment. A total of 128 men were recruited online through Prolific Academic and paid $£ 1$ (approx. \$1.32) for their time. Of these recruits, 22 failed to complete the survey and were excluded from analyses, leaving a final sample of 106 men, all of whom were over the age of 18 and identified as heterosexual British nationals. Due to the sensitive nature of the topic, and in hopes of encouraging truthful responding by emphasizing anonymity, no further demographic information was gathered.

\section{Procedure, Materials and Measures}

The study was conducted online. Participants were randomly assigned to either a control condition $(n=54)$, in which they viewed an image of a woman in everyday clothing (a dark blue top and white skirt), or a sexualized condition $(n=52)$, in which they viewed an image of the same woman in a bikini (teal and polka dotted). Both images depicted the same young attractive model - a thin Caucasian woman with her hair down. The images were taken from the thighs up, and the woman was similarly posed and front facing, looking into the camera and smiling. In both conditions, the woman depicted in the image they viewed was given the following generic description: "The woman below is a recent graduate 
from a psychology program in the United Kingdom. She enjoys spending time with friends and dating." All participants were then instructed to briefly write about the woman they viewed. Participants in the control condition received the following instructions: "Please take some time to write about this person. Focus on both positive and negative aspects," whereas those in the sexualized condition received these instructions: "Please take some time to write about this person's appearance. Focus on both positive and negative aspects." This writing prompt manipulation was based on the one used by Heflick and Goldenberg (2009, see also Heflick et al. 2011). Following the manipulation, all participants completed two manipulation check measures concerning attributions of human nature and human uniqueness regarding the woman about whom they wrote. Next, three outcome variables were assessed in randomized order: a Rape Behavior Analogue (RBA), modified Attraction to Sexual Aggression Inventory (m-ASAI), and modified Attitudes toward Rape Victims Scale (m-ARVS).

Human Nature and Human Uniqueness Scales The same scales measuring human nature $(\alpha=.75)$ and human uniqueness $(\alpha=.74)$ used in Study 1 were used here (Bastian et al. 2012).

Rape Behavior Analogue (RBA) Study 2 employed a Rape Behavior Analogue based on the sexual imposition method (cf. Rudman and Mescher 2012), using the same images as in the cited study. This task involved presenting participants with 17 image pairs, each containing one aggressive and one sexually aggressive image. Participants were instructed:

Imagine you are working to help select pictures for an upcoming study. Along with other women, the woman you wrote about will be participating in this study. It will involve women being exposed many times to a subset of the images you choose, to test perception. For this next task, we will show you two pictures and we would like you to pick the one you think should be used in the women's study. Pick the one you think should be shown to the woman you wrote about many times.

Scores were computed by assigning 0 to choices of violent images and 1 to sexually violent images, then summing (possible range: $0-17$ ).

\section{Modified Attraction to Sexual Aggression Inventory (M-ASAI)}

We again used the ASAI (Malamuth 1989) to assess rape proclivity. However, the scale was modified such that items and instructions were worded in relation to the woman viewed/written about by participants. Two items that could not be altered to make sense in this changed context were excluded, resulting in a 12 -item scale $(\alpha=.82)$. The items that were removed were items 1 and 2 from the original scale, which asked about the frequency of having had certain thoughts; because participants were being asked about a specific and novel woman, these items were not applicable here.

Modified Attitudes Toward Rape Victims Scale (M-ARVS) Unfavorable attitudes toward victims of rape was assessed using the ARVS (Ward 1988), which was modified in our study to relate each item and the instructions to the woman the participants viewed and wrote about. One item which did not make sense in this context was excluded, resulting in a 24item scale $(\alpha=.89)$. The excluded items stated: "Accusations of rape by bar girls, dance hostesses, and prostitutes should be viewed with suspicion," which was irrelevant to the specific target woman who did not meet these criteria.

\section{Results}

T-tests on the human nature and human uniqueness measures show that our manipulation was effective. The woman in the control condition was perceived as having greater human nature qualities $(M=5.31, S E=.13)$ than the same woman in the sexualized condition $(M=4.85, S E=.14), t(104)=2.43$, $p=.017, d=.48$. The same pattern of results was found for human uniqueness, with the woman in the control condition perceived as having more human uniqueness qualities $(M=$ $5.20, S E=.12)$ than the same woman in the sexualized condition $(M=4.69, S E=.15), t(104)=2.58, p=.011, d=.55$. However, contrary to predictions, no significant mean differences between conditions were found for the outcome variables, including the m-ASAI, m-ARVS, or the RBA, $t s(104)$ $<.913, p s>.363$.

Pearson's correlations were computed for all measures and can be found in Table 4 along with overall descriptive statistics. The left half of Table 5(a) contains the correlations for all study variables broken down by condition. Additionally, the difference between each condition's correlations were tested, and the significance of these tests can be found in the right half of Table 5(b). For each cell, we tested whether the strength of the correlation between variables differed significantly based on condition (whether a participant saw the control woman or saw the sexualized woman). We calculated these comparisons of correlations to explore for more subtle conditional differences that did not translate into mean group differences that would be detected by the planned $t$-tests.

Significant differences were found between the correlations by condition for human uniqueness on all outcome measures, including the m-ASAI, m-ARVS, and RBA, such that the negative correlation between human uniqueness and each outcome was strengthened when the sexualized woman was viewed. In other words, when viewing a sexualized woman, the negative correlation between human uniqueness and each 
Table 4 Descriptive statistics and correlations, study 2

\begin{tabular}{|c|c|c|c|c|c|c|c|}
\hline \multirow[b]{2}{*}{ Variable Name } & \multirow[b]{2}{*}{$M(S D)$} & \multirow[b]{2}{*}{ n (Possible Scores) } & \multicolumn{5}{|c|}{ Correlations } \\
\hline & & & 1 & 2 & 3 & 4 & 5 \\
\hline 1. Human Nature & $5.08(.99)$ & $106(1-7)$ & - & & & & \\
\hline 2. Human Uniqueness & $4.95(1.03)$ & $106(1-7)$ & $.637 * *$ & - & & & \\
\hline 3. m-ASAI & $1.36(.44)$ & $106(1-5)$ & $-.338 * *$ & $-.192 *$ & - & & \\
\hline 4. m-ARVS & $1.73(.57)$ & $106(1-5)$ & -.100 & $-.348 * *$ & $.368 * *$ & - & \\
\hline 5. RBA & $7.14(4.72)$ & $106(1-17)$ & -.117 & -.070 & $.320 * *$ & $.240 *$ & - \\
\hline
\end{tabular}

$m$-ASAI modified Attraction to Sexual Aggression Inventory (measuring rape proclivity), $m$-ARVS modified Attitudes toward Rape Victims Scale (measuring unfavorable attitudes toward rape victims)

$* p<.05 . * * p<.01$

sexual aggression-related outcome measure was stronger than the correlation when viewing the control woman image. Human nature showed significant differences between correlations by condition on the RBA only, again such that this negative relationship was stronger when the sexualized woman was viewed.

\section{Discussion}

Despite the lack of group mean differences, Study 2 revealed important differences in correlations based on experimental condition. These differences between correlations indicate that when a woman is dressed in everyday clothing, the role of dehumanization is negligible in whether men report interest in perpetrating sexual aggression against her. By sharp contrast, when women are sexualized, these factors - particularly attributions of human uniqueness - play a strong role in her being seen as a potential victim of sexual aggression. This pattern represents evidence of a relationship between the sexualization of a target and the likelihood that some men will show a proclivity to both dehumanize and sexually aggress against that women.

The role of human uniqueness in driving the effects we found here, across all the measures of sexual aggression we examined, is an especially interesting result of our study. Human uniqueness is the dimension of humanity associated with distinguishing humans from animals and includes attributions of traits such as intelligence and rationality. Human nature involves those aspects that are considered essentiallynot exclusively - human, such as emotionality and warmth. When a person is denied human uniqueness, as was the case in the results of interest here, they are seen in terms of more animalistic or bestial traits (animalistic dehumanization). When denied human nature, people are viewed as cold and mechanical (mechanistic dehumanization). Because our results relied heavily on denial of human uniqueness in
Table 5 Correlations between variables by condition and significance of differences between correlations by condition, study 2

\begin{tabular}{|c|c|c|c|c|c|c|c|c|c|}
\hline \multirow[b]{2}{*}{ Variable } & \multicolumn{5}{|c|}{ (a) Correlations } & \multicolumn{4}{|c|}{$\begin{array}{l}\text { (b) Significance of Difference in } \\
\text { Correlations }^{\text {a }}\end{array}$} \\
\hline & 1 & 2 & 3 & 4 & 5 & 2 & 3 & 4 & 5 \\
\hline 1. Human Nature & - & $.695 * *$ & $-.406^{*}$ & $-.286^{* *}$ & $-.319 * *$ & .170 & .563 & .103 & $.043^{*}$ \\
\hline $\begin{array}{l}\text { 2. Human } \\
\text { Uniqueness }\end{array}$ & $.523 * *$ & - & $-.399 * *$ & $-.577 * *$ & $-.328^{*}$ & - & $.042 *$ & $.021 *$ & $.005^{*}$ \\
\hline 3. m-ASAI & $-.305^{*}$ & -.015 & - & $.357 * *$ & $.469 * *$ & & - & .899 & .126 \\
\hline 4. m-ARVS & .032 & -.193 & $.379 * *$ & - & $.314 *$ & & & - & .429 \\
\hline 5. RBA & .074 & .219 & .200 & .165 & - & & & & - \\
\hline
\end{tabular}

Correlation for the sexualized Woman Condition are reported above the diagonal of the correlation matrix; for the control woman condition, below

$m$-ASAI modified Attraction to Sexual Aggression Inventory (measuring rape proclivity), $m$-ARVS modified Attitudes toward Rape Victims Scale (measuring unfavorable attitudes toward rape victims), RBA Rape Behavior Analogue

$* p<.05 . * * p<.01$

${ }^{a}$ the significance of the difference between the pair of correlations for the Sexualized Woman condition and Control conditions 
particular, it seems that some men dehumanize potential victims of sexual aggression in a very specific way, which relies on seeing them as relatively animal-like. Thus, sexualized women in particular are seen as less deserving of the concern and respect attributed to a fully human entity and may be considered more violable in turn.

\section{General Discussion}

In a pair of studies, we examined whether dehumanization and objectification are related to men's sexual aggression interests and attitudes toward women in general (Study1), as well as toward a specific female target (Study 2). Study 1 showed correlational links between dehumanization and men's sexual aggression-related attitudes and interests. Critically, dehumanization mattered despite controlling for a set of additional factors that could otherwise explain variance in male sexual aggression. The results for objectification, on the other hand, were unexpected and more sporadic. The results concerning dehumanization from Study 1 directly informed the predictors used in Study 2.

Study 2 replicated the correlations concerning dehumanization and extended these results to provide some experimental evidence of a relationship among attitude and interest factors, as well as a behavioral analogue of sexual aggression. Although we did not find the expected mean group differences, we did find a subtler effect in differences between strength of correlations. In Study 2 the effects were clearest when broken down by condition, showing stronger correlations between dehumanization and sexual aggression attitudes and interests for a sexually objectified woman. Additionally, we could break down the effect of dehumanization in our second study, and we found that it seems to be primarily driven by denial of human uniqueness to that woman, especially when she is sexualized. The effects in both studies appeared to be most strongly linked with the most heinous forms of sexual aggression (e.g., rape proclivity).

Taken together in the context of a growing literature on dehumanization and objectification as they relate to sexual aggression, our findings genuinely extend our knowledge of what elements of dehumanization are most relevant to sexually aggressive attitudes and interests in men, as well as when these are most likely to be involved in perpetrators' perceptions of women as potential victims. More specifically, this pair of studies replicates and extends the previously established knowledge of a role for dehumanization and objectification (Loughnan et al. 2013; Rudman and Mescher 2012) by introducing additional levels of control that take into account the literature on sexual aggression as a whole. We also add novel direct experimental evidence of a causal role of this set of potential victim attributions in explicit perpetrator appraisals. In other words, most critical to the extension of scientific knowledge in our work was the level of control we used in attempting to test the correlational role of dehumanization and objectification as robustly as possible in Study 1, which was then extended via a data-driven experimental test of causation in Study 2. By including mechanistic and animalistic dehumanization in empirical work on male proclivity toward sexual aggression, we lend support to intuitive and theoretical links between these factors (Dworkin and MacKinnon 1985, 1988; Kelland 2011) and point to directions for future research and applications for this pressing worldwide problem.

\section{Limitations}

We did not find a consistent relationship between objectification as a manifestation of dehumanization, and sexual aggression. However, the lack of findings for the measure of objectification may relate to the nature of the scale itself more than the potential role of objectification. Objectification is multifaceted, with multiple theoretical conceptualizations (Fredrickson and Roberts 1997; Nussbaum 1999). Although widely used, the OOQ only allows for measurement of one aspect of objectification, which may be less important for sexual aggression compared with other facets that could be tapped by different measures. This measure is also typically used with a particular reference person in mind, which was not the case in Study 1 here, and hence this may represent an additional limitation. Given the negative correlations found between objectification and sexually harassment interest, the role of objectification should be addressed further in future research by using a more appropriate measure, perhaps a more behavioral report, such as the Interpersonal Sexual Objectification Scale (Davidson et al. 2013; Kozee et al. 2007).

Although our work provides evidence linking dehumanization and sexual aggression, there are several limitations to these findings that we should acknowledge. In Study 1, we did have a relatively small sample for powering the tests which controlled for known correlates of our outcome measures. Also, in Study 1 we did use a reference woman for the measures of dehumanization. Although we did this because it is consistent with how the measures are typically used in other literature, it may have primed participants to think of this woman for the remaining measures, in contrast to their unprimed responding to the measure of objectification.

Additionally, our manipulation in Study 2 failed to elicit mean group differences. This occurred despite pre-testing our image stimuli and combining previously successful manipulations (Heflick and Goldenberg 2009; Heflick et al. 2011; Loughnan et al. 2010; Pacilli et al. 2017). One possibility is that this was a result of the specific stimuli images we used, which could represent a limitation of the study's generalizability. Additionally, the present work may be limited by the 
specific cultural (British) and social context (online) in which it was conducted. Future work could examine alternate manipulations to explore whether differences in sexual aggression occur at a mean group differences level as well as correlationally. A stronger manipulation may be necessary to elicit mean group differences in future research, and lab or naturalistic studies should be undertaken to further investigate this important topic beyond online samples and British men.

Although we did use self-report measures for most manifestations of sexual aggression attitudes and interests, evidence from other work (Gidycz et al. 2011b) indicates that men are often aware of and able to accurately report their likelihood to engage in these behaviors. Thus, this may not represent a limitation of the present work in the usual sense. One particular self-report, our measure of sexual harassment interest, failed to show any effects when control factors were included. However, we believe it is unlikely that the failure of the Likelihood to Sexually Harass scale to relate to dehumanization and objectification was a result of responding in selfenhancing ways, especially given that results did appear for the more extreme forms of sexual aggression that we measured. The measure of sexual harassment interest was limited in that it specifically informed respondents that there would be no hypothetical consequences of their actions, but indeed the failure to find an effect under these circumstances, which could hypothetically have enhanced scores, may represent stronger evidence that dehumanization and objectification only relate to more extreme forms of sexual aggression and not to more everyday forms of sexual harassment.

\section{Future Directions}

Our work provides a necessary and timely foundation for further research exploration of these important issues. We focused on how some men's dehumanization and objectification of women predicts their own sexual aggression. Given that other men will hold dehumanizing and objectifying beliefs, and the legitimating behavior of other men is robustly associated with men's sexual aggression (Mitchell et al. 2002; Gidycz et al. 2011a), exploring the social dynamics of dehumanization and objectification is an important future direction. It may well be that men who objectify together, also offend together - or enable, legitimate, or tolerate others' offending. There is tentative evidence for this possibility. We know that men (and women) who objectify female victims of sexual and non-sexual violence care about them less (Loughnan et al. 2013; Pacilli et al. 2017). Understanding whether bystander objectification can precipitate, foster, or hide others' offending is an important future direction and could be applied to the development of interventions and preventions.

Furthermore, research could build more generally toward understanding whether the effect is altered with the inclusion of variables that are relevant to the real-world contexts in which sexual aggression is most likely to occur. One such variable is alcohol use and misuse, which has a wellestablished relationship with sexual aggression broadly (cf. George and Marlatt 1986; Davis et al. 2006, 2008, 2009) and which has been shown to be mediated by objectification (Gervais et al. 2014; Haikalis et al. 2015). Based on this body of work, adding the role of dehumanization, particularly animalistic dehumanization, to alcohol studies of sexual aggression could be a fruitful future direction. A second avenue for research based on Study 2 is to examine whether sexualization primes (which are so common in the modern world that they are difficult to avoid) beyond the sexualization of the particular woman in question are sufficient to activate the relationship between dehumanization and sexual aggression we showed here. Future work should be specifically designed with the complexity of real-world contexts and applied uses in mind.

\section{Practice Implications}

By improving our understanding of sexual aggression and the factors that contribute to its perpetration, our studies have the potential to aid in the development of more effective prevention efforts and education, as well as to inform interventions and social policy. One major take-away message from our work is that although dehumanization and objectification of women are certainly nasty beliefs to hold and should be eliminated in their own right, not all men who hold them will have an interest in sexual aggression. Indeed, only in certain circumstances will these factors be related. Our work also points to the importance of emphasizing women's particular traits that relate to humanness, and especially human uniqueness, when designing efforts in the service of ultimately reducing sexual aggression perpetration. Additionally, this emphasis may be especially relevant in either therapeutic or educational settings when working with men who are known to be at a high risk of perpetration based on their individual personality traits such as those factors we used as controls in Study 1. Furthermore, previous intervention efforts for prevention of sexual aggression have often relied on bystanders (Banyard et al. 2003; Coker et al. 2011; Gidycz, et al. 2011a, b), and incorporating an emphasis on women's humanness into these programs could represent a subtler strategy bystanders could be taught to use to direct the attention of a potential perpetrator away from acting harmfully.

\section{Conclusion}

The present work aimed to contribute to research on the antecedents of violence against women with the ultimate hope of adding to the growing empirical literature for determining those individual and social factors that are most related to men's endorsement of sexually aggressive attitudes and 
interests. Our pair of studies was successful in this aim by establishing robust correlational, as well as experimental, evidence of a role of dehumanization in explicit reports of male sexual aggression attitudes and interests. It is imperative that we work to reduce male sexual aggression toward women, and our studies highlight two important, previously underexamined components: mechanistic and animalistic dehumanization.

Acknowledgments The authors would like to acknowledge the role of the Leverhulme Prize to the second author in funding this work.

Funding Steve Loughnan has received funding from the Leverhulme Prize that contributed to this work.

\section{Compliance with Ethical Standards}

Conflict of Interests The authors declare that they have no other potential conflicts of interest.

Research Involving Human Participants and Informed Consent This study involved human participants, all of whom underwent informed consent prior to participation.

Open Access This article is distributed under the terms of the Creative Commons Attribution 4.0 International License (http:// creativecommons.org/licenses/by/4.0/), which permits unrestricted use, distribution, and reproduction in any medium, provided you give appropriate credit to the original author(s) and the source, provide a link to the Creative Commons license, and indicate if changes were made.

Publisher's Note Springer Nature remains neutral with regard to jurisdictional claims in published maps and institutional affiliations.

\section{References}

Abbey, A., McAuslan, P., \& Ross, L. T. (1998). Sexual assault perpetration by college men: The role of alcohol, misperception of sexual intent, and sexual beliefs and experiences. Journal of Social and Clinical Psychology, 17(2), 167-195. https://doi.org/10.1521/jscp. 1998.17.2.167.

Abbey, A., McAuslan, P., Zawacki, T., Clinton, A. M., \& Buck, P. O. (2001). Attitudinal, experiential, and situational predictors of sexual assault perpetration. Journal of Interpersonal Violence, 16(8), 784 807. https://doi.org/10.1177/088626001016008004.

Abbey, A., Jacques-Tiura, A. J., \& LeBreton, J. M. (2011). Risk factors for sexual aggression in young men: An expansion of the confluence model. Aggressive Behavior, 37(5), 450-464. https://doi.org/10. 1002/ab.20399.

Abrams, D., Viki, G. T., Masser, B., \& Bohner, G. (2003). Perceptions of stranger and acquaintance rape: The role of benevolent and hostile sexism in victim blame and rape proclivity. Journal of Personality and Social Psychology, 84(1), 111-125. https://doi.org/10.1037/ 0022-3514.84.1.111.

Anderson, K. B., Cooper, H., \& Okamura, L. (1997). Individual differences and attitudes toward rape: A meta-analytic review. Personality and Social Psychology Bulletin, 23(3), 295-315. https://doi.org/10. 1177/0146167297233008.
Banyard, V. L., Plante, E. G., \& Moynihan, M. M. (2003). Bystander education: Bringing a broader community perspective to sexual violence prevention. Journal of Community Psychology, 32(1), 61-79. https://doi.org/10.1002/jcop.10078.

Basile, K. C., Chen, J., Black, M. C., \& Saltzman, L. E. (2007). Prevalence and characteristics of sexual violence victimization among U.S. adults, 2001-2003. Violence and Victims, 22(4), 437448 Retrieved from https://search.proquest.com/docview/ 208557771 ?accountid=10673.

Bastian, B., Jetten, J., \& Radke, H. R. M. (2012). Cyber-dehumanization: Violent video game play diminishes our humanity. Journal of Experimental Social Psychology, 48, 486-491. https://doi.org/10. 1016/j.jesp.2011.10.009.

Bernard, P., Loughnan, S., Marchal, C., Godart, A., \& Klein, O. (2015). The exonerating effects of sexual objectification: Sexual objectification decreases rapist blame in a stranger rape context. Sex Roles, 72, 499-508. https://doi.org/10.1007/s11199-015-0482-0.

Breiding, M. J., Smith, S. G., Basile, K. C., Walters, M. L., Chen, J., \& Merrick, M. T. (2014). Prevalence and characteristics of sexual violence, stalking, and intimate partner violence victimizationNational intimate partner and sexual violence survey, United States, 2011 (surveillance summaries, 68, 8). Atlanta: Center for Surveillance, Epidemiology, and Laboratory Services, Centers for Disease Control and Prevention (CDC), U.S. Department of Health and Human Services.

Burkley, M., Wong, Y. J., \& Bell, A. C. (2016). The Masculinity Contingency Scale (MCS): Scale development and psychometric properties. Psychology of Men \& Masculinity, 17(2), 113-125. https://doi.org/10.1037/a0039211.

Bushman, B. J., Bonacci, A. M., van Dijk, M., \& Baumeister, R. F. (2003). Narcissism, sexual refusal, and aggression: Testing a narcissistic reactance model of sexual coercion. Journal of Personality and Social Psychology, 84(5), 1027-1040. https://doi.org/10.1037/ 0022-3514.84.5.1027.

Calogero, R. M. (2004). A test of objectification theory: The effect of the male gaze on appearance concerns in college women. Psychology of Women Quarterly, 28, 16-21. https://doi.org/10.1111/j.1471-6402. 2004.00118.x.

Calogero, R., Davis, W. N., \& Thompson, J. K. (2005). The role of selfobjectification in the experience of women with eating disorders. Sex Roles, 52(1/2), 43-50. https://doi.org/10.1007/s11199-0051192-9.

Chabrol, H., Leeuwen, N. V., Rodgers, R., \& Sejourne, N. (2009). Contributions of psychopathic, narcissistic, Machiavellian, and sadistic personality traits to juvenile delinquency. Personality and Individual Differences, 47, 734-739. https://doi.org/10.1016/j.paid. 2009.06.020.

Coker, A. L., Cook-Craig, P. G., Williams, C. M., Fisher, B. S., Clear, E. R., Garcia, L. S., \& Hegge, L. M. (2011). Evaluation of green dot: An active bystander intervention to reduce sexual violence on college campuses. Violence Against Women, 17(6), 777-796. https:// doi.org/10.1177/1077801211410264.

Davidson, M. M., Gervais, S. J., Canivez, G. L., \& Cole, B. P. (2013). A psychometric examination of the interpersonal sexual objectification scale among college men. Journal of Counseling Psychology, 60(2), 239-250. https://doi.org/10.1037/a0032075.

Davis, K. C., Norris, J., George, W. H., Martell, J., \& Heiman, J. R. (2006). Men's likelihood of sexual aggression: The influence of alcohol, sexual arousal, and violent pornography. Aggressive Behavior, 32, 581-589. https://doi.org/10.1002/ab.20157.

Davis, K. C., Schraufnagel, T. J., George, W. H., \& Norris, J. (2008). The use of alcohol and condoms during sexual assault. American Journal of Men's Health, 2(3), 281-290. https://doi.org/10.1177/ 1557988308320008.

Davis, K. C., Stoner, S. A., Norris, J., George, W. H., \& Masters, N. T. (2009). Women's awareness of and discomfort with sexual assault 
cues effects of alcohol consumption and relationship type. Violence Against Women, 15(9), 1106-1125. https://doi.org/10.1177/ 1077801209340759.

Dworkin, A., \& MacKinnon, C. A. (1985). The reasons why: Essays on the new civil rights law recognizing pornography as sex discrimination. New York: Women Against Pornography.

Dworkin, A., \& MacKinnon, C. A. (1988). Pornography and civil rights: A new day for women's equality. New York: Organizing Against Pornography.

Fisher, B. S., Daigle, L. E., \& Cullen, F. T. (2010). Unsafe in the ivory tower: The sexual victimization of college women. Thousand Oaks: Sage Publications, Inc..

Fredrickson, B. L., \& Roberts, T. A. (1997). Objectification theory: Toward understanding women's lived experiences and mental health risks. Psychology of Women Quarterly, 21(2), 173-206. https://doi. org/10.1111/j.1471-6402.1997.tb00108.x.

Fredrickson, B. L., Roberts, T., Noll, S. M., Quinn, D. M., \& Twenge, J. M. (1998). That swimsuit becomes you: Sex differences in selfobjectification, restrained eating, and math performance. Journal of Personality and Social Psychology, 75, 269-284.

Gannon, T. A., Collie, R. M., Ward, T., \& Thakker, J. (2008). Rape: Psychopathology, theory and treatment. Clinical Psychology Review, 28(6), 982-1008. https://doi.org/10.1016/j.cpr.2008.02.005.

Garcia-Moreno, C., Jansen, H., Ellsberg, M., Heise, L., \& Watts, C. H. (2006). Prevalence of intimate partner violence: Finding from the WHO multi-country study on women's health and domestic violence. The Lancet, 368(9543), 1260-1269. https://doi.org/10.1016/ S0140-6736(06)69523-8.

George, W. H., \& Marlatt, G. A. (1986). The effects of alcohol and anger on interest in violence, erotica, and deviance. Journal of Abnormal Psychology, 95(2), 150-158. https://doi.org/10.1037/0021-843x.95. 2.150 .

Gervais, S. J., DiLillo, D., \& McChargue, D. (2014). Understanding the link between men's alcohol use and sexual violence perpetration: The mediating role of sexual objectification. Psychology of Violence, 4(2), 156-169. https://doi.org/10.1037/a0033840.

Gidycz, C. A., Orchowski, L. M., \& Berkowitz, A. D. (2011a). Preventing sexual aggression among college men: An evaluation of a social norms and bystander intervention program. Violence Against Women, 17(6), 720-742. https://doi.org/10.1177/ 1077801211409727

Gidycz, C. A., Warkentin, J. B., Orchowski, L. M., \& Edwards, K. M. (2011b). College men's perceived likelihood to perpetrate sexual aggression. Journal of Aggression, Maltreatment \& Trauma, 20, 260-279. https://doi.org/10.1080/10926771.2011.562480.

Glick, P., \& Fiske, S. T. (1996). The ambivalent sexism inventory: Differentiating hostile and benevolent sexism. Journal of Personality and Social Psychology, 70(30), 491-512.

Greitmeyer, T., \& McLatchie, N. (2011). Denying humanness to others: A newly discovered mechanism by which violent video games increase aggressive behavior. Psychological Science, 22(5), 659665. https://doi.org/10.1177/0956797611403320.

Guizzo, F., \& Cadinu, M. (2017). Effects of objectifying gaze on cognitive performance: The role of flow experience and internalization of beauty ideals. British Journal of Social Psychology, 56(2), 281-292. https://doi.org/10.1111/bjso.12170.

Haikalis, M., DiLillo, D., \& Gervais, S. J. (2015). Up for grabs? Sexual objectification as a mediator between women's alcohol use and sexual victimization. Journal of Interpersonal Violence, 32(4), 1-22. https://doi.org/10.1177/0886260515586364.

Hall, G. C. N., \& Hirschman, R. (1991). Toward a theory of sexual aggression: A quadripartite model. Journal of Consulting and Clinical Psychology, 59(5), 662-669. https://doi.org/10.1037/ 0022-006x.59.5.662
Haslam, N. (2006). Dehumanization: An integrative review. Personality and Social Psychology Review, 10(3), 252-264. https://doi.org/10. 1207/s15327957pspr1003 4.

Haslam, N., \& Loughnan, S. (2014). Dehumanization and infrahumanization. Annual Review of Psychology, 65, 399-423. https://doi.org/10.1146/annurev-psych-010213-115045.

Haslam, N., Bain, P., Douge, L., Lee, M., \& Bastian, B. (2005). More human than you: Attributing humanness to self and others. Journal of Personality and Social Psychology, 89(6), 937-950. https://doi org/10.1037/0022-3514.89.6.937.

Heflick, N. A., \& Goldenberg, J. L. (2009). Objectifying Sarah Palin: Evidence that objectification causes women to be perceived as less competent and less fully human. Journal of Experimental Social Psychology, 45, 598-601. https://doi.org/10.1016/j.jesp.2009.02. 008.

Heflick, N. A., Goldenberg, J. L., Cooper, D. P., \& Puvia, E. (2011). From women to objects: Appearance focus, target gender, and perceptions of warmth, morality and competence. Journal of Experimental Social Psychology, 47, 572-581. https://doi.org/10.1016/j.jesp. 2010.12.020.

Heilbrun, A. B., \& Loftus, M. P. (1986). The role of sadism and peer pressure in the sexual aggression of male college students. The Journal of Sex Research, 22(3), 320-332. https://doi.org/10.1080/ 00224498609551312.

Hersh, K., \& Gray-Little, B. (1998). Psychopathic traits and attitudes associated with self-reported sexual aggression in college men. Journal of Interpersonal Violence, 13(4), 456-471. https://doi.org/ $10.1177 / 088626098013004003$

Jacobs, J. (2018, September 20). Anita Hill's testimony and other key moments from the Clarence Thomas hearings. The New York Times. Retrieved January, 2019 from https://www.nytimes.com/2018/09/ 20/us/politics/anita-hill-testimony-clarence-thomas.html.

Johnson, S. M., Murphy, M. J., \& Gidycz, C. A. (2017). Reliability and validity of the sexual experiences survey- short forms victimization and perpetration. Violence and Victims, 32(1), 78-92. https://doi.org/ 10.1891/0886-6708.VV-D-15-00110.

Jones, D. N., \& Paulhus, D. L. (2014). Introducing the Short Dark Triad (SD3): A brief measure of dark personality traits. Assessment, 21(1), 28-41. https://doi.org/10.1177/1073191113514105.

Kelland, L. (2011). Conceptually situating the harm of rape: An analysis of objectification. South African Journal of Philosophy, 30(2), 168 183. https://doi.org/10.4314/sajpem.v30i2.67779.

Knight, R. A., \& Cerce, D. D. (1999). Validation and revision of the multidimensional assessment of sex and aggression. Psychologica Belgica, 39(2-3), 135-161.

Knight, R. A., \& Prentky, R. A. (1990). Classifying sexual offenders: The development and corroboration of taxonomic models. In W. L. Marshall, D. R. Laws, \& H. E. Barbaree (Eds.), The handbook of sexual assault (pp. 23-52). New York: Plenum.

Knight, R. A., Prentky, R. A., \& Cerce, D. D. (1994). The development, reliability, and validity of an inventory for the multidimensional assessment of sex and aggression. Criminal Justice and Behavior, 21(1), 72-94.

Kosson, D. S., Kelly, J. C., \& White, J. W. (1997). Psychopathy-related traits predict self-reported sexual aggression among college men. Journal of Interpersonal Violence, 12(2), 241-254. https://doi.org/ 10.1177/088626097012002006.

Kozak, M., Frankenhauser, H., \& Roberts, T.-A. (2009). Objects of desire: Objectification as a function of male sexual orientation. Psychology of Men \& Masculinity, 10(3), 225-230. https://doi.org/ 10.1037/a0016257.

Kozee, H. B., Tylka, T. L., Augustus-Horvath, C. L., \& Denchik, A. (2007). Development and psychometric evaluation of the interpersonal sexual objectification scale. Psychology of Women Quarterly, 31, 176-189. https://doi.org/10.1111/j.1471-6402.2007.00351.x. 
Lackie, L., \& de Man, A. F. (1997). Correlates of sexual aggression among male university students. Sex Roles, 37(5/6), 451-457. https://doi.org/10.1023/A:1025613725757.

Leidner, B., Castano, E., \& Ginges, J. (2013). Dehumanization, retributive and restorative justice, and aggressive verses diplomatic intergroup conflict resolution strategies. Personality and Social Psychology Bulletin, 39(2), 181-192. https://doi.org/10.1177/ 0146167212472208 .

Leyens, J., Rodriguez-Perez, A., Rodriguez-Torres, R., Gaunt, R., Paladino, M., Vaes, J., \& Demoulin, S. (2001). Psychological essentialism and the differential attribution of uniquely human emotions to ingroups and outgroups. European Journal of Social Psychology, 31, 395-411. https://doi.org/10.1002/ejsp.50.

Loughnan, S., Haslam, N., Murnane, T., Vaes, J., Reynolds, C., \& Suitner, C. (2010). Objectification leads to depersonalization: The denial of mind and moral concern to objectified others. European Journal of Social Psychology, 40, 709-717. https://doi.org/10.1002/ejsp.755.

Loughnan, S., Pina, A., Vasquez, E. A., \& Puvia, E. (2013). Sexual objectification increases rape victim blame and decreases perceived suffering. Psychology of Women Quarterly, 37(4), 455-461. https:// doi.org/10.1177/0361684313485718.

Loughnan, S., Fernandez-Campos, S., Vaes, J., Anjum, G., Aziz, M., Harada, C., \& Tsuchiya, K. (2015). Exploring the role of culture in sexual objectification: A seven nations study. Revue Internationale de Psychologie Sociale, 28(1), 125-152.

Loughnan, S., Baldissarri, C., Spaccatini, F., \& Elder, L. (2017). Internalizing objectification: Objectified individuals see themselves as less warm, competent, moral, and human. British Journal of Social Psychology, 56, 217-232. https://doi.org/10.1111/bjso. 12188.

Malamuth, N. M. (1989). The attraction to sexual aggression scale: Part one. The Journal of Sex Research, 26(1), 26-49. https://doi.org/10. 1080/0022449890955149.

Malamuth, N. M. (1996). The confluence model of sexual aggression: Feminist and evolutionary perspectives. In D. B. Buss \& N. M. Malamuth (Eds.), Sex, power, conflict: Evolutionary and feminist perspectives (pp. 269-295). New York: Oxford University Press.

Malamuth, N. M. (2003). Criminal and noncriminal sexual aggressors. Annals of the New York Academy of Sciences, 989(1), 33-58. https:// doi.org/10.1111/j.1749-6632.2003.tb07292.x.

Malamuth, N. M., Socklosckie, R. J., Koss, M. P., \& Tanaka, J. S. (1991). Characteristics of aggressors against women: Testing a model using a national sample of college students. Journal of Consulting and Clinical Psychology, 59(5), 670-681. https://doi.org/10.1037/ 0022-006x.59.5.670

Malamuth, N. M., Linz, D., Heavey, C. L., Barnes, G., \& Acker, M. (1995). Using the confluence model of sexual aggression to predict men's conflict with women: A 10-year follow up study. Journal of Personality and Social Psychology, 69(2), 353-369. https://doi.org/ 10.1037/0022-3514.69.2.353.

Malamuth, N. M., Heavey, C. L., \& Linz, D. (1996). The confluence model of sexual aggression: Combining hostile masculinity and impersonal sex. Journal of Offender Rehabilitation, 23(3-4), 13-37. https://doi.org/10.1300/J076v23n03 03.

Malamuth, N. M., Heavey, C. L., \& Linz, D. (2013). Predicting men's antisocial behavior against women: The interaction model of sexual aggression. In G. C. N. Hall, R. Hirschman, J. R., Graham, \& M. S. Zaragoza (Eds.), Sexual aggression: Issues in etiology, assessment, and treatment (pp. 63-97). Philadelphia: Taylor \& Francis.

Marshall, W. L., \& Barbaree, H. E. (1990). An integrated theory of sexual offending. In W. L. Marshall, D. R. Laws, \& H. E. Barbaree (Eds.), Handbook of sexual assault: Issues, theories and treatment of the offender (pp. 363-385). New York: Plenum.

Masser, B., Viki, G. T., \& Power, C. (2006). Hostile sexism and rape proclivity amongst men. Sex Roles, 54, 565-574. https://doi.org/ 10.1007/s11199-006-9022-2.
Mikorski, R., \& Szymanski, D. M. (2016). Masculine norms, peer group, pornography, facebook, and men's sexual objectification of women. Psychology of Men \& Masculinity, 18, 257-267. https://doi.org/10. 1037/men0000058.

Mitchell, D., Angelone, D. J., Hirschman, R., Lilly, R. S., \& Nagayama Hall, G. C. (2002). Peer modeling and college men's sexually impositional behavior in the laboratory. The Journal of Sex Research, 39(4), 326-333. https://doi.org/10.1080/ 00224490209552157.

Moradi, B., \& Huang, Y. (2008). Objectification theory and psychology of women: A decade of advances and future directions. Psychology of Women Quarterly, 32, 377-398. https://doi.org/10.1111/j.14716402.2008.00452.x.

Moradi, M., Dirks, D., \& Matteson, A. V. (2005). Roles of sexual objectification experiences and internalization of standards of beauty in eating disorder symptomology: A test and extension of objectification theory. Journal of Counseling Psychology, 52(3), 420-428. https://doi.org/10.1037/0022-0167.52.3.420.

Morris, K. L., Goldenberg, J., \& Boyd, P. (2018). Women as animals, women as objects: Evidence for two forms of objectification. Personality and Social Psychology Bulletin, 44(9), 1302-1314. https://doi.org/10.1177/0146167218765739.

Multidimensional Inventory of Development, Sex, and Aggression (MIDSA). (2011). Multidimensional inventory of development, sex, and aggression (MIDSA) clinical manual (3rd ed.). Bend: Augur Enterprises Available at www.midsa.us.

Muñoz-Rivas, M. J., Graña, J. L., O’Leary, D., \& González, M. P. (2009). Prevalence and predictors of sexual aggression in dating relationships of adolescents and young adults. Psicothema, 21(2), 234-240.

Noll, S. M., \& Fredrickson, B. L. (1998). A mediational model linking self-objectification, body shame, and disordered eating. Psychology of Women Quarterly, 22(4), 623-636. https://doi.org/10.1111/j. 1471-6402.1998.tb00181.x.

Nussbaum, M. (1999). Objectification. In M. Nussbaum (Ed.), Sex and social justice (pp. 213-239). New York: Oxford University Press.

Pacilli, M. G., Pagliaro, S., Loughnan, S., Gramazio, S., Spaccatini, F., \& Baldry, A. C. (2017). Sexualization reduces helping intentions towards female victims of intimate partner violence through mediation of moral patiency. British Journal of Social Psychology, 56, 293313. https://doi.org/10.1111/bjso.12169.

Parent, M. C., \& Moradi, B. (2009). Confirmatory factor analysis of the conformity to masculine norms inventory and development of the conformity to masculine norms Inventory-46. Psychology of Men \& Masculinity, 10(3), 175-189. https://doi.org/10.1037/a0015481.

Parent, M. C., \& Moradi, B. (2011). An abbreviated tool for assessing conformity to masculine norms: Psychometric properties of the conformity to masculine norms Inventory-46. Psychology of Men \& Masculinity, 12(4), 339-353. https://doi.org/10.1037/a0021904.

Paulhus, D. L., \& Williams, K. M. (2002). The dark triad of personality: Narcissism, Machiavellianism, and psychopathy. Journal of Research in Personality, 36, 556-563. https://doi.org/10.1016/ S0092-6566(02)00505-6.

Pithers, W. D. (1990). Relapse prevention with sexual aggressors: A method for maintaining therapeutic gains and enhancing external supervision. In W. L. Marshall, D. R. Laws, \& H. E. Barbaree (Eds.), Handbook of sexual assault: Issues, theories, and treatment of the offender (pp. 343-363). New York: Plenum.

Pryor, J. B. (1987). Sexual harassment proclivities in men. Sex Roles, 17(5/6), 269-290. https://doi.org/10.1007/BF00288453.

Reston, M. (2018, September 27). 'I will never forget': Christine Blasey Ford recounts her trauma in raw testimony. CNN Politics. Retrieved January, 2019 from https://edition.cnn.com/2018/09/27/politics/ christine-blasey-ford-raw-testimony/index.html.

Rudman, L. A., \& Mescher, K. (2012). Of animals and objects: Men's implicit dehumanization of women and likelihood of sexual 
aggression. Personality and Social Psychology Bulletin, 38(6), 734 746. https://doi.org/10.1177/0146167212436401.

Sanchez, D. T., \& Kiefer, A. K. (2007). Body concerns in and out of the bedroom: Implications for sexual pleasure and problems. Archives of Sexual Behavior, 36(6), 808-820. https://doi.org/10.1007/ s10508-007-9205-0.

Seabrook, R. C., Ward, L. M., \& Giaccardi, S. (2016). Why is fraternity membership associated with sexual assault? Exploring the roles of conformity to masculine norms, pressure to uphold masculinity, and objectification of women. Psychology of Men \& Masculinity, 19, 3 13. https://doi.org/10.1037/men0000076.

Smith, S. G., Chen, J., Basile, K. C., Gilbert, L. K., Merrick, M. T., Patel, N., ... Jain, A. (2017). The National Intimate Partner and sexual violence survey (NISVS): 2010-2012 state report. Atlanta: National Center for Injury Prevention and Control Centers for Disease Control and Prevention. Retrieved from https://stacks.cdc.gov/ view/cdc/46305.

Steer, A., \& Tiggemann, M. (2008). The role of self-objectification in women's sexual functioning. Journal of Social and Clinical Psychology, 27(3), 205-225. https://doi.org/10.1521/jscp.2008.27. 3.205 .

Stoltenborgh, M., van Ijzendoorn, M. H., Euser, E. M., \& BakermansKranenburg, M. J. (2011). A global perspective on child sexual abuse: Meta-analysis of prevalence around the world. Child Maltreatment, 16(2), 79-101. https://doi.org/10.1177/ 1077559511403920.

Strelan, P., \& Hargreaves, D. (2005). Women who objectify other women: The vicious circle of objectification? Sex Roles, 54(9), 707-712. https://doi.org/10.1007/s11199-005-3737-3.

Szymanski, D. M., \& Henning, S. L. (2007). The role of selfobjectification in women's depression: A test of objectification theory. Sex Roles, 56, 45-53. https://doi.org/10.1007/s11199-0069147-3.

Tiggeman, M., \& Kuring, J. K. (2004). The role of body objectification in disordered eating and depressed mood. British Journal of Clinical Psychology, 43, 299-311. https://doi.org/10.1348/ 0144665031752925.

Tjaden, P., \& Thoennes, N. (1998). Prevalence, incidence, and consequences of violence against women: Findings from the National Violence against Women Survey. Washington, DC: U. S.
Department of Health and Human Services, Centers for Disease Control and Prevention.

Tjaden, P., \& Thoennes, N. (2000). Prevalence and consequences of male-to-female and female-to-male intimate partner violence as measured by the national violence against women survey. Violence Against Women, 6(2), 142-161. https://doi.org/10.1177/ 10778010022181769.

Tylka, T. L., \& Hill, M. S. (2004). Objectification theory as it relates to disordered eating among college women. Sex Roles, 51(11/12), 719-730. https://doi.org/10.1007/s11199-004-0721-2.

Vaes, J., Paladino, P., \& Puvia, E. (2011). Are sexualized women complete human beings? Why men and women dehumanize sexually objectified women. European Journal of Social Psychology, 41, 774-785. https://doi.org/10.1002/ejsp.824.

Vasquez, E. A., Ball, L., Loughnan, S., \& Pina, A. (2017). The object of my aggression: Sexual objectification increases physical aggression toward women. Aggressive Behavior, 44(1), 5-17. https://doi.org/ 10.1002/ab.21719.

Walby, S., \& Allen, J. (2004). Domestic violence, sexual assault and stalking: Findings from the British crime survey (Home Office Research Study 276). London: Home Office Research, Development and Statistics Directorate.

Ward, C. (1988). The attitudes toward rape victims scale: Construction, validation, and cross-cultural applicability. Psychology of Women Quarterly, 12, 127-146. https://doi.org/10.1111/j.1471-6402.1988. tb00932.x.

Ward, T., \& Beech, T. (2005). An integrated theory of sexual offending. Aggression and Violent Behavior, 11, 44-63. https://doi.org/10. 1016/j.avb.2005.05.002.

Ward, T., \& Hudson, S. M. (1998). A model of the relapse process in sexual offenders. Journal of Interpersonal Violence, 13, 700-725. https://doi.org/10.1177/088626098013006003.

Wrench, J. S. (2002). The impact of sexual orientation and temperament on physical and verbal aggression. Journal of Intercultural Communication Research, 31, 85-106.

Yost, M. R., \& Zurbriggen, E. L. (2006). Gender differences in the enactment of sociosexuality: An examination of implicit social motives, sexual fantasies, coercive sexual attitudes, and aggressive sexual behavior. The Journal of Sex Research, 43(2), 163-173. https:// doi.org/10.1080/00224490609552311. 